\title{
Measuring cohesion indicators in middle school: membership, implication and satisfaction
}

Andreia Ștefănescu, Ion Albulescu, Petre Daniel Cârciag, Diana Mariana Boeriu, Editha Margareta Coșarbă 


\title{
Measuring cohesion indicators in middle school: membership, implication and satisfaction
}

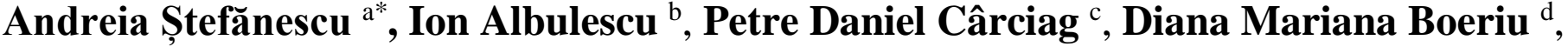 \\ Editha Margareta Coșarbă
}

\begin{abstract}
aDoctoral School "Educational, Reflection, Development", Babes-Bolyai University, 7 Sindicatelor Street, 400029, Cluj-Napoca, Romania ${ }^{b}$ Faculty of Psychology and Educational Sciences, Babeș-Bolyai University Cluj-Napoca, 7 Sindicatelor Street, 400029, Romania ${ }^{c}$ Doctoral School, The National University of Physical Education and Sport, 140 Constantin Noica Street, Bucharest, 060057, Romania 'Doctoral School "Educational, Reflection, Development", Babeş-Bolyai University, 7 Sindicatelor Street, 400029, Cluj-Napoca, Romania 'Doctoral School "Educational, Reflection, Development", Babeș-Bolyai University, 7 Sindicatelor Street, 400029, Cluj-Napoca, Romania

*Corresponding author: stefanescu.andreia@gmail.com
\end{abstract}

\section{Abstract}

Keywords:

membership, group

cohesion, class climate, cooperation, psycho-social group

Zusammenfasung

Schlüsselworte:

Mitgliedschaft,

Gruppenkohäsion,

Klassenklima, Kooperation,

psycho-soziale Gruppe
The current article investigates the validation of a scale designed to measure cohesion within class groups (middle school level) taking into account various number of cohesion indicators, such as: belonging to a group and analysing the relationships between its members, the level of implication and participation of the members in activities, the satisfaction of the members towards being part of their group related to the benefits. The questionnaire that includes the scale was distributed to a sample (the selection was determined theoretically). All the respondents were middle school pupils. The results are tracking how the cohesion scale is validated taking into account the statistical perspective and the content of the items in relation with the research's objectives.

Der vorliegende Artikel untersucht die Validierung einer Skala, die entwickelt wurde, um den Zusammenhalt innerhalb von Klassengruppen zu messen und dabei eine Reihe von Kohäsionsindikatoren zu berücksichtigen, wie z. B.: die Zugehörigkeit zu einer Gruppe und die Analyse der Beziehungen zwischen ihren Mitgliedern, der Grad der Einbindung und Beteiligung der Mitglieder an Aktivitäten, die Zufriedenheit der Mitglieder mit der Zugehörigkeit zu ihrer Gruppe in Bezug auf die Vorteile. Der Fragebogen, der die Skala enthält, wurde an eine Stichprobe verteilt (die Auswahl wurde theoretisch bestimmt). Alle Befragten waren Sekundarschüler. Die Ergebnisse verfolgen die Validität der Kohäsionsskala unter Berücksichtigung der statistischen Perspektive und des Inhalts der Items in Bezug auf die Ziele der Forschung.

\section{Introduction}

The group of pupils can be defined as a group of individuals connected by relations (similar goals and interests) and common features.

When thinking about a class group from a psychosocial perspective we must associate this with a psychosocial group. The class group is mainly oriented towards learning but many other components are also involved such as formative and relational ones (Johnson and Johnson,2003; Senge, 2016).

The class group becomes a group the very moment when its members are participating in solving common tasks in order to reach an objective shared by the entire group. This way the group helps each and every member to stay focused upon the task and members help each other. Instead of having the teacher control members' behaviorpupils are taking this responsibility as well as the group (Hadfield, 1992).

The work environment and the colleagues involved, getting involved into different competitions with an increased degree of efficiency and cooperating in order to solve particular tasks determines both changes at a cognitive level and behavioral and relational level (Hogg, 1992). The way the group dynamics is built during the fifth grade will be the foundation upon which the class group culture will be constituted during the middle school.

The purpose of the present study is to validate the content of a scale designed to determine statistically the intensity of some particular cohesion indicators as we aim to further evaluate the correlations between the dependent and independent variables of the present research. 


\section{Theoretical background}

The group cohesion represents a phenomenon through which the members of a group are attracted to the group by the specific functions: control, influence, pressure to uniformity. The result will be a strong allegiance and unity experienced by "us" (Cristea, 2015).

Moreover, this approach is a particular one to which the international agreements haveto answer when it comes to some particular attributes of the group such socialising and integrating within the educational environment. The cohesion determines obedience to the groups' rules, stability and also provides behavioral control to its members (Hogg, 1992).

Pupils are social beings with social needs such as acceptance, membership and power that must be accomplished within groups (Sausage 1991). If their social requirements are met then they find the real capability to build a cohesive group. This is the path educators should choose to build cohesion through promoting it between pupils. OECD also defines cohesion through its social dimension as a sense of belonging to the school's community and the educational environment (OECD, 2010).

In 2015 'th Pisa testing pupils were asked to report how they feel inside the school community: whether they feel left-out or they can easily make friends as they feel to belong to their school or by the contrary, they feel uncomfortable, if they feel that their classmates like them or if they feel alone. Same questions were asked as part of PISA enquiries leading to the capacity of the educational systems to monitor changes that occurred in the commitment of pupils towards their school communities. As school is a primary environment accommodating social interactions of adolescents the results of these subjective evaluations indicate whether the educational systems are endorsed to evaluate pupils' well-being or not.

The answers given by pupils to these questions were used to build the indicator needed to measure the sense of belonging. The indicator was then standardized with a medium value established at 0 and a standard deviation of 1 within all OECD member countries. On this scale the positive value indicates that the pupil proves a higher sense of belonging compared to the medium value of the indicator reported by the EU member countries.

On average, in 2015 , in member countries, $73 \%$ of pupils indicated that they feel like they belong to their school. $78 \%$ of the pupils agreed they can easily make friends at school. $85 \%$ expressed their disagreement to the assertion that they feel alone in school while $83 \%$ disagreed with the idea that they feel left-out by their school community. An average of $82 \%$ felt accepted by other pupils and peers while $81 \%$ disagreed with the assertion that they feel uncomfortable at school. Most of the pupils feel like they are socially connected to their schools. Even so, in some countries we identified the presence of representative minor groups whose members felt isolated or lonely (OECD, 2017, p. 118).

Comparing the results of the PISA enquiry in 2004, 2012 and 2015 we notice that within all OECD countries the sense of belonging has decreased on average between 2012 and 2015. The percentage of the pupils who have disagreed or strongly disagreed regarding the topic of loneliness has decreased as an average with approx. 6 points during the time we took into account.

This particular trend indicates a gradual decrease of their sense of belonging to their schools (2003-2015). In 2003 approx. $7 \%$ of the pupils reported they feel like strangers; by 2012 this ratio increased with $4 \%$ and by 2015 it increased by $10 \%$. The ratio hasn't significantly decreased in the member countries between 2003-2015 (OECD, 2017, p. 119).

The culture of the class group represents ,the group's way of life, that includes all the habits, rules, values, myths and rituals" (Negovan, 2006, p. 151). The class culture is included by: the way the learning process is conducted, the characteristics of the physical environment and the interactions between its members (ibidem, p. 151). How these things are taking place inside the class group is determined by the cohesion level of the group (Sălăvăstru, 2004).

The cohesion determines the psycho-social climate of the class represented by the psychological state-of-mind of the group. This is an essential factor when it comes to class management (Woolfolk, 1993).

The class management is determined by specific particularities of the activities taking place within the group. The psycho-social climate determined by a high cohesion level is defined by the following features:

a. "Trust and mutual exigencies of the members of the group;

b. The benevolent and pragmatic critics;

c. Freedom of opinion concerning the issues of the group;

d. Lack of pressure from teachers to pupils and giving pupils the right to take important decisions for the whole group;

e. Accurate briefing of the members of the group concerning the problems and the status of different issues;

f. The level of the satisfaction concerning the belonging to the group;

g. The level up to which and the mutual assistance the members get into various situations that imply emotional frustrations"(Krâsiko, 2007, p. 142).

An investigation conducted in 12 schools in the UK, Senior (1997), indicated in her study based upon observations and group interviews the main characteristics of the cohesive class as described by the pupils in middle school: a sense of respect and trust, acceptance of the abilities and limits, a sense of cooperation and mutual support, a sense of relaxation and comfort, a safe environment. 
The same author conducted another research implying four secondary classes (the 5th and the 6th grade). She then shared the idea of integrating specific cohesion activities as she reported that teachers use different types of tasks in order to adjust to the social and pedagogical priorities. For example, collecting information tasks are used as teachers are aiming to reach a particular pedagogical goal but at the very same time teachers are using these strategies to promote cooperative learning between pupils. They have to interact to complete the tasks therefore focusing rather upon the information then upon the appearance.

The final result is that pupils will get to know each other better and the respect level will increase. Mutual acceptance will then be reached(Senior, 2004).

Combining learning with cooperation techniques in classroom activities can be really beneficial to increase group cohesion. It contributed to

- reducing the anxiety

- promoting interactions

- increasing self-confidence

- raising motivation

- opening new opportunities for pupils to develop intercultural understanding respect and friendship

- creating social skills, they need in the process of acceptance of different opinions and getting to a consensus

- obtaining a greater efficiency in learning and increasing pupil's focus (Crandall, 1999, pp. 233-239).

Brumfit (1984) says the class group should be built as a psychological group in order to ensure the efficiency of the work and facilitate an active interaction between the pupils.

Dörnyei and Murphey (2003) say particular subjects should be conducted as group activities because within a „good" group teachers and pupils enjoy the learning process and feel comfortable in a pleasant, challenging and supportive environment. The key factor is common motivation.

Theoretical sources (George, 1990; Hackman, 1990; Hogg, 1992; Kaymak, 2011) and studies that focused upon cohesion research within groups (Beal, Cohen, Burke and McLendon, 2003; Casey-Campbell and Martens, 2009; Karau and Williams, 1997; Moody and White, 2003) as well as researches focused upon cohesion in class groups (Bulgaru, 2015; Fotopoulou, Zafeiropoulos and Alegre, 2019; Zakriski, Seifer, Sheldrick et al., 1999; Wilt, Veen, Kruistum and Oers, 2018) have mentioned a few theoretical and aplicative prerequisites we used in this study in elaborating a scale comprising the most used reliable and valid cohesion indicators in order to measure this phenomenon at secondary classes.

Our study focuses upon an objective we chose from the doctoral approach therefore we will further refer to validating the content of the cohesion scale as described in the section below.

\section{The research's design}

\subsection{Aim and objectives of the research}

The aim of this research is to create and validate the content of a scale to measure the cohesion phenomenon in middle school groups of pupils.

The objectives of the research are:

O1. To create a scale to measure the cohesion phenomenonin middle school pupils and to validate its content

O2. To use the scale in order to measure cohesion in middle school pupilsthrough the following indicators:

a. The extent of belonging to the class group with the emphasizing of the relations between pupils

b. The implication and participation at common activities level

c. How satisfactory the quality of being a member of the group is through identifying benefits the members get from their group

The indicators above are expressed by the items of the questionnaire presented in Annex 1.

O3. To evaluate the measure up to which the scale provides significant information concerning the cohesion phenomenon within the class group.

\subsection{The research sample}

The scale was implemented on a number of 580 secondary pupils from various schools in Romania (boys and girls, from both urban and rural environments from five counties).

Sampling was theoretical and exhaustive and all pupils belonged to the classes we have included in the middle school lot we have previously identified.

The sample's distribution was heterogeneous as we were less interested in the differences related to social and demographic features and more interested in studying the climate of the class groups. We also referred to the suggestions from various studies to correlate the sample's accuracy with our research aims (Cohen, Manion and Morrison, 2007).

563 questionnaires were valid and therefore this is the dimension of the final sample of our research. If significant differences will occur the results will be discussed accordingly.

\subsection{Methodology: the instrument and the} procedure

The instrument we used was a Likert scale questionnaire with five options (the scale as proposed for validation, see the Appendix). The scale as designed by us following the objectives of the research.

The questionnaire comprises, apart from the datacollecting questions, a number of 24 items constructed to measure several dimensions of cohesion. 12 of these items are negative.

The questions cover three aggregate indicatorsdesigned by us combining the information provided bymethodological literature (Hogg, 1992; Kaplan, 1990), as follows: 
Table 1. Indicators, abbreviations, and item's quotation

\begin{tabular}{|l|l|l|l|l|l|l|}
\hline No. & Cohesion indicator & Abbreviations & $\begin{array}{l}\text { Positive } \\
\text { quoted items }- \\
\text { Questions }\end{array}$ & Abbreviations & $\begin{array}{l}\text { Negative } \\
\text { quoted items }- \\
\text { Questions }\end{array}$ & Abbreviations \\
\hline 1 & $\begin{array}{l}\text { The group belongingness } \\
\text { concerning } \\
\text { relationships between } \\
\text { pupils }\end{array}$ & A & $5,11,13,21$ & A_positive & $6,8,10,22$ & A_negative \\
\hline 2 & $\begin{array}{l}\text { Implication and } \\
\text { participation in group's } \\
\text { activities }\end{array}$ & B & $1,9,17,19$ & B_positive & $2,4,16,18$ & B_negative \\
\hline 3 & $\begin{array}{l}\text { Satisfaction provided by } \\
\text { the membership through } \\
\text { identifying benefits }\end{array}$ & C & $3,7,15,23$ & C_positive & $12,14,20,24$ & C_negative \\
\hline
\end{tabular}

The above items include already validated elements regarding relation between cohesion and different variables. As example we can provide research papers that studied statistical correlations between cohesion indicators and other variables (Bettenhausen, 1991; Carron and Brawley, 2000; Hogg, 1992; Erdley, Nangle and Gold, 1998).

The research instrument was conceived according to the rules and limitations as mentioned in scientific researches. Also, in preparing questions data analysis and qualitative interpretation of the results we used reference scientific studies, validates in other enterprises as well. (Bryman and Cramer, 2008; Chelcea, 1994; Kaplan, 1990).

The scale was implemented to subjects from secondary school to measure their understanding upon the questions and if they can identify themselves by answering them. The data was analysed under the aspect of the accuracy of the measuring process and the internal consistency of the inner values. The reliability and validity of the scale in measuring the constructs was testedby Cronbach's Alpha coefficient. This coefficient varies between 0 and 1 but in order to significantly influence the latent variable the minimal value has to be 0,7 (Hair et al., 2006).

\section{The results}

The answers to the scale's questions produced the following results (aggregated data):

Cronbach's Alpha' coefficient values for latent variables exceeds the minimal value $(\mathrm{A}=0,775 ; \mathrm{B}=0,727 ; \mathrm{C}=0.711)$ meaning that the subject managed to answer the questions.
Table 2. Cronbach's Alpha coefficient values for latent variables

\begin{tabular}{|l|l|l|}
\hline The latent variable & $\begin{array}{l}\text { Cronbach's } \\
\text { Alpha }\end{array}$ & $\begin{array}{l}\text { No. of } \\
\text { items }\end{array}$ \\
\hline $\begin{array}{l}\text { The belonging to the group } \\
\text { aiming pupils' interrelations } \\
\text { (A) }\end{array}$ & 0,775 & 8 \\
\hline $\begin{array}{l}\text { Implication and participation to } \\
\text { group's activities (B) }\end{array}$ & 0,727 & 8 \\
\hline $\begin{array}{l}\text { The level of satisfaction given } \\
\text { by the membership through } \\
\text { identifying the benefits pupils } \\
\text { get from their group (C) }\end{array}$ & 0.711 & 8 \\
\hline Total & 0.888 & 24 \\
\hline
\end{tabular}

The result confirms the fact that the scale can be validated as being reliable and can be used with secondary pupils and can be replicated within similar investigations.

The descriptive statistics for the entire sample provide information about cohesion for each indicator.

The belonging to the group (Apositive) is being identified as high proving positive relations between pupils:

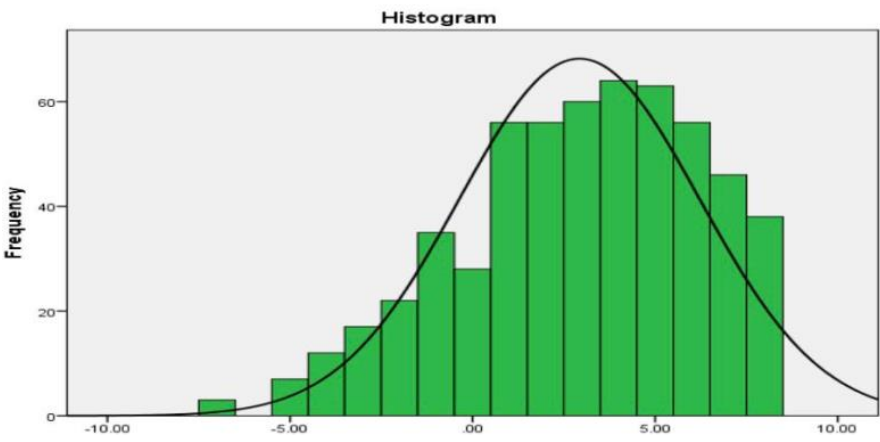

Figure 1. The belonging to the group (Apositive), for the entire sample 
The Gauss's curve in Figure 1 (the answers' distribution depending upon scores associated with pupils' answers) is right-oriented. The meaning of this orientation is that the respondents considered that assertions targeting this indicator are suitable to them. We took into consideration all data collected for the entire sample. Furthermore, the statistically significant trend is related to bonding with mates (standard deviation is 3.293 and the score for average value is 2.925 )

All the above being taken into consideration we can assert that relatedness within the class group (relating with others, appreciation, openness, assertiveness) gives to the majority of subjects the sense of belonging to the group and most of its members feel good as members of their groups.

The reversed items related to the belonging to the group (A negative) refer to the appreciations concerning the sense of exclusion and poor bonding with peers and group. That indicates a complementary distribution from the A positive set of questions:

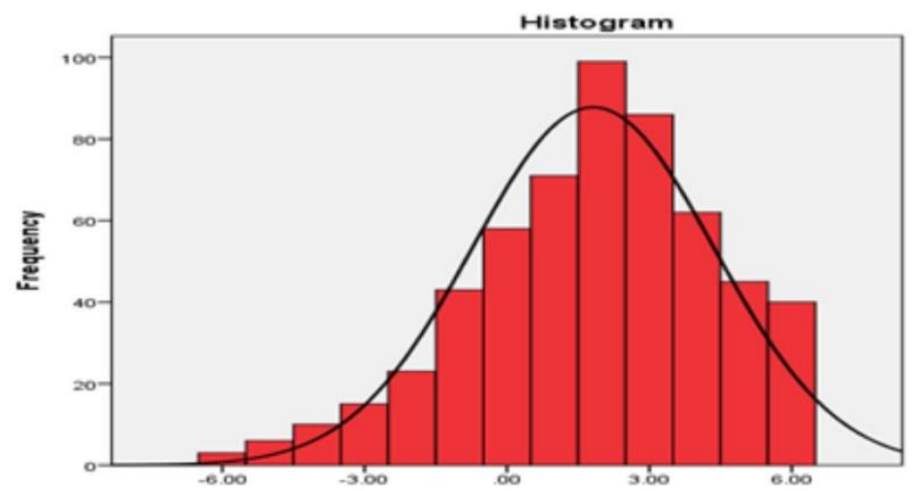

Figure 2. The non-belonging to the group (A negative), for the entire sample

In this figure we can observe a standard deviation of Gauss's Curve. The value is 2.549 and the average score (statistically) is 1.815 . As a consequence, the aggregated answers are placed under the average theoretical score related to the entire sample. Therefore, less than $50 \%$ of pupils feel they cannot establish positive connections with the group (they feel disliked, they do not ask for help or hide their problems, their opinions are not valued).

Implication and participation to group's activities (Figure 3):

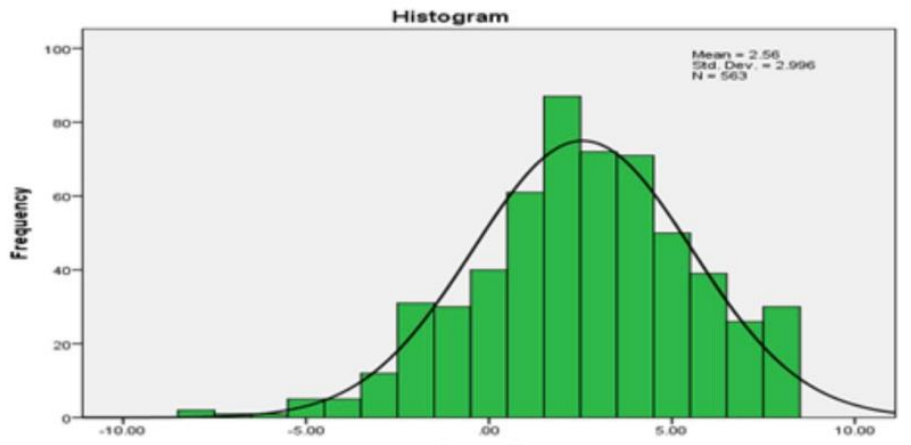

Figure 3. Implication and participation to group's activities (B positive), for the entire sample
Analysing this indicator, we notice that statistical data suggest an average level of implication and participation of the group (B positive). The score average is 2.556 and standard deviation is 2,996 meaning that pupils appreciate the dimension of the cohesion being weaker compared to the relatedness one.

The general trend of the sample's opinion gets confirmed by the distribution of the results we've got for the implication and non-implication indicator (B negative):

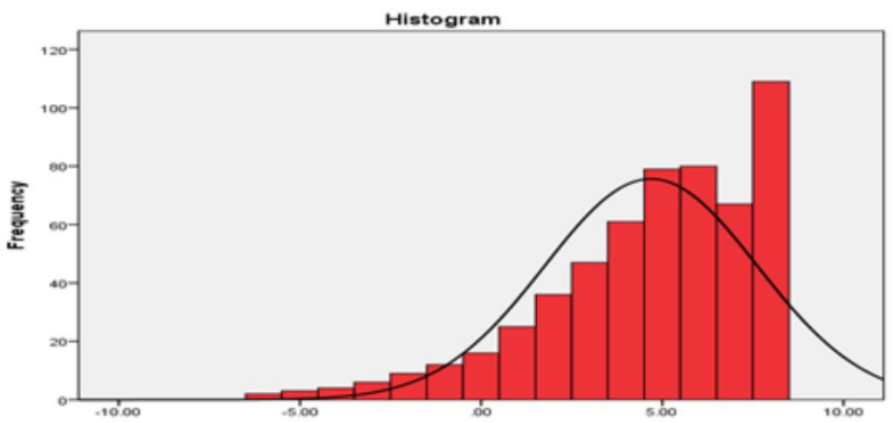

Figure 4. Non-implication and non-participation to group's activities (B negative), for the entire sample

According to the histogram above pupils have given higher scores (the average is 4.689) to the reversed items describing implication and participation in group activities. This aggregated indicator refers to a range of elements such as: cooperation, activism or confidence about the power and strength of the group, in relation to the common objectives.

This leads us to the conclusion that we are getting a disturbing signal when it comes to the configuration of the components of groups. Many pupils feel excluded or do not feel empowered by the class's opinion to carry on different tasks, they do not resent pleasure when they perform various activities and are not committed.

The degree up to which pupils get satisfaction or nonsatisfaction is somehow similar if we refer to the indicator „The level of satisfaction given by the membership through identifying the benefits pupils get from their group". This conclusion is only valid within the context of the discussion about group belonging and related only to particular dimensions as follows:

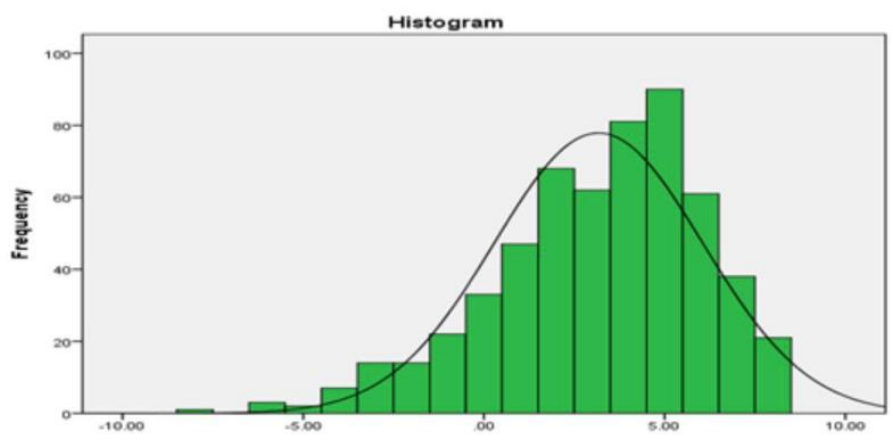

Figure 5. The level of satisfaction given by the membership through identifying the benefits pupils get from their group ( $\mathrm{C}$ positive), for the entire sample 
The score's average for these answers(they feel good at school, they feel happy when the group is successful and proud to be its members, they feel they can ask other members for help) is 3.168 therefore is placed at a higher rank while the standard deviation is 2.890. But if we look at the scores registered by the reversed items of this indicator, we can appreciate that the group belonging indicator reveals that pupils do not perceive the membership as a benefit or a satisfaction. The average score is 4.920 the highest compared to the other average scores related to cohesion indicators. The standard deviation for this aggregate indicator is 2.965 as shown in the figure below:

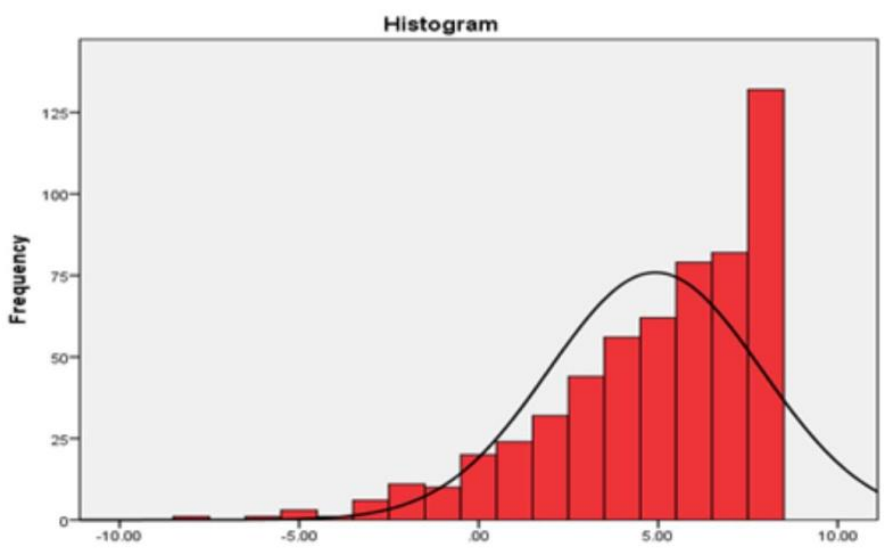

Figure 6 . The level of non-satisfaction given by the membership ( $\mathrm{C}$ negative), for the entire sample

The items of this indicator are significant for the issues generated by assessing the non-belonging to their group by many pupils: getting help from peers gets the lowest value, pupils hardly feel they are part of the group, a good result is individual not collective and there isn't pride for being a member of the group.

The results including signification tests as they were calculated for the entire sample are shown below (Table 3):

Table 3. Descriptive statistics for the entire sample

\begin{tabular}{|l|l|l|l|l|l|l|}
\hline & Minimum & Maximum & Mean & Std. Deviation & Skewness & Kurtosis \\
\cline { 2 - 7 } & Statistic & Statistic & Statistic & Statistic & Statistic & Statistic \\
\hline Apositive & -7.00 & 8.00 & 2.925 & 3.293 & -.474 & -.361 \\
Anegative & -6.00 & 6.00 & 1.815 & 2.549 & -.477 & -.009 \\
Bpositive & -8.00 & 8.00 & 2.556 & 2.996 & -.332 & .106 \\
Bnegative & -6.00 & 8.00 & 4.689 & 2.932 & -1.027 & .848 \\
Cpositive & -8.00 & 8.00 & 3.168 & 2.890 & -.690 & .335 \\
Cnegative & -8.00 & 8.00 & 4.920 & 2.965 & -1.100 & .990 \\
\hline
\end{tabular}

Score average per class groups is shown in Table 4:

Table 4.Average score per class groups

\begin{tabular}{|l|l|l|l|l|l|l|}
\hline CLASS & A-POSITIVE & A-NEGATIVE & B- POSITIVE & B-NEGATIVE & C-POSITIVE & C-NEGATIVE \\
\hline V & 3.0694 & 1.4965 & 2.6849 & 4.1806 & 3.2708 & 4.7413 \\
\hline VI & 3.2410 & 1.8415 & 2.4074 & 4.7125 & 3.4699 & 5.2651 \\
\hline VII & 2.3597 & 1.4965 & 2.2878 & 4.8074 & 2.9275 & 4.2662 \\
\hline VIII & 3.0863 & 2.2589 & 2.7107 & 4.9695 & 3.1357 & 5.3618 \\
\hline
\end{tabular}

As we can see from the data above the indicator that measures the belonging to the class group for the VII ${ }^{\text {th }}$ and the VIII ${ }^{\text {th }}$ grade gets a higher positive score than the one for the $\mathrm{V}^{\text {th }}$ and $\mathrm{VI}^{\text {th }}$ grade. However significantly many pupils in the $\mathrm{VI}^{\text {th }}$ grade report an increase of the non-belonging sense. That also happens because they need to psychologically and socially adapt to the specific puberty stages.
Furthermore, the indicator assessing the implication and participation within common group activities is quite low as a global score (is situated below the average scores) and slightly increases in the VIII ${ }^{\text {th }}$ grade. The graphics of the reversed items is also linear but here we must emphasize that significantly more pupils contributed with their appreciations towards the obstacles preventing implication and participating in groups' activities. 
The satisfaction level given by the quality of being a member of the group registers a higher-than-average score for the $\mathrm{V}^{\text {th }}$ and the $\mathrm{VI}^{\text {th }}$ grade. It lowers for pupils in the VII ${ }^{\text {th }}$ and VIII ${ }^{\text {th }}$ grade. Instead, the reversed items (describing a lack of satisfaction for this issue) is the highest for $\mathrm{VI}^{\text {th }}$ and VIII ${ }^{\text {th }}$ grades both in the general image of the scores and within this indicator. This can lead us to the conclusion that the educational system fails when it comes to facilitate integration for the members of class groups. Here we appreciate that integrative activities should also refer to giving consistent and efficient legitimacy to group members and also support for pupils who feel lonely or shy or rebel pupils as a reaction to rules, tasks or group demands.

\section{Conclusions}

Considering all data presented above we can elaborate the following conclusions and discussions:

- This research confirms the results of other studies indicating multiple dimensions of the cohesion, the complexity of the factors that intervene within the process of establishing relationships between pupils and within its dynamics. As this is preliminary research, we cannot firmly assert overall conclusions but it sets particular trends that have been checked using specific and valid instruments. It is the starting point from which we will extend our research the very moment the scale becomes valid. Furthermore, we will begin the correlational statistical analysis of the variables generated by the research's objectives.

- It is compulsory to determine through further testing if all members of a class group have the same thoughts and feelings about the cohesion of their group. But the results we will get using the scale are promising. As we know what sensitive cohesion elements are and the exact grade they tend to appear we can then identify solutions in order to reduce the sense of non-belonging, isolation, inadequacy.

- The results we have reached are not necessarily positive for schools but it is possible to correlate results showing vulnerabilities concerning the dimension of cohesion with existing resources (human and material resources, other). This way we can avoid the syndrome of „us, teachers" vs „they, the pupils”. Cohesion in school refers also to teachers-pupils relationships.

- From all results we have got through this research, participation and commitment to group projects seems to be the weaker indicator. Therefore, we consider it is important to identify the origin of this perception. It is possible that socio-cultural homogenous groups that are constituted by pupils with high academic performances to experience a higher sense of cohesion. A probable cause is that those particular groups have more self-confidence granted by results and other rewards while groups having less wellprepared pupils may become defensive. That being the case, those pupils will segregate from the "successful" group in terms of interests and activities. The question arising is how can we transform the process so that it becomes a desirable one? From poor academic results- humiliation-losing interest for school and group leaving we have to aim towards high academic performance-prideacknowledgement-inclusion. If we manage to do so then we can ensure cohesion of the class-group. We will continue our research in order to discover using analysis and applicative instruments to answer this question.

- The main limitation of this study is the manner we dealt with the aggregation of the scores provided by individuals' responses we have treated as a group construction. Klein, Danserauand Hall (1994) proved that in order to create a reliable opinion's image all individuals should get the same score on a particular variable. If this is the case (very unlikely in sample-based research) all individuals in a group would get even scores from aggregated indicators of the scale's items. But the present research is based upon particular perceptions of a particular issue (consisting in both appreciations and opinions about the cohesion) rather than upon the objective construct of this notion. Also, measuring the relatedness, participation and belonging we have used in this study through the validation of the scale was obtained at a group level by diminishing the variance of the construct itself.

- This study uses transversal data to solve a problem that is a longitudinal one at his core (the evolution of the sense of cohesion from the $\mathrm{V}^{\text {th }}$ to VIII ${ }^{\text {th }}$ grade). The temporal effect of the groups' dynamics is a very interesting subject, As a consequence, the dynamics of the building of the cohesion as a longitudinal phenomenon would justify additional investigations.

- This study comes as an addition to the conclusions of other valid studies. The subject is very actual and gives lots of opportunities as it needs to be deeply investigated. Many studies we have mentioned in the theoretical section (Bettenhausen, 1991; Casey-Campbell and Martens, 2009; Kaymak, 2011) encourages researchers to investigate factors and previous events that led to the cohesion of the group as a known phenomenon with a wide range of positive effects on the dynamics of the class group and underlying the academic performance. These studies prove that there are many values connected to the personal as well as team's effort related to cultural relational values (including friendship), the desire for success and attitudes towards performance that are disseminated through the group. From this point of view our study didn't referred to elements that may be significant when it comes to the interpretation of the results. Specifically, we mention the effects of past group's experiences that may have had generate effects on subjects, collective low self-esteem and group performance over building group's cohesion.

- If people responsible for the management and architecture of the cohesion strategies in schools would gather valid information about specific conditions that have a positive impact upon building and developing class groups in secondary school that would obviously generate positive effects upon the class's climate and academic performance. These effects would be gradual and 
progressive and so from the $\mathrm{V}^{\text {th }}$ to VIII ${ }^{\text {th }}$ grade the group would become a real support for its members with positive influences on the well-being and academic performance of each and every member. The scale that makes the object of this research was designed to be a valid background instrument to help accomplish the above goal.

\section{Authors note:}

Andreia Ștefănescu is currently the President of the Romanian Association for Research and Innovation which provides professional training courses for teachers accredited by the Ministry of Education and Research. She is also a Ph.Dstudent at Babeș-Bolyai University ClujNapoca. Her field of interests include the phenomenon of cohesion within schools groups.

Ion Albulescu is habilitated Professor and $\mathrm{Ph} . D . C o o r d i n a t o r$ at the Faculty of Psychology and Sciences ofEducation (Babeş-Bolyai University, ClujNapoca,Romania) Department of Educational Sciences, Facultyof Psychology and Educational Sciences. His researchinterest is reflected in a series of studies, articles andbooks published by prestigious international and nationaleditors. The Professor Albulescu teaching and researcharea covers several educational domains such asEducational Alternatives, Comparative Education,Pedagogical Theories and History of EducationalThinking etc.

Petre Daniel Cârciag is a Ph. D.student at the Doctoral School of the Faculty of physical Education and Sports at the University of Bucharest, Headteacher of Inclusive Education Center Băbeni.

Diana Mariana Boeriu is a preschool teacher. She is a Ph.D.student at Babeș-Bolyai University Cluj-Napoca. Her field of interest includethe implication of modern games and toys use in socio-emotional development of preschool pupils.

Editha Margareta Coșarbă has been a full-time teacher in pre-university education for 15 years. Currently, she is a Ph.D. student at Babeș-Bolyai University in Cluj-Napoca. Her field of interest includes non-formal educational activities.

\section{References}

Beal, D.J., Cohen, R.R., Burke, M.J.,\&McLendon, C.L. (2003). Cohesion and Performance in Groups: A MetaAnalytic Clarification of Construct Relations, Journal of Applied Psychology, 88, 989-1004.
Bettenhausen, K.L. (1991). Five years of group research: what we have learned and what needs to be addressed. Journal of Management, Vol. 17, No. 2, 345-381.

Brumfit, C. (1984). Communicative Methodology in Language Teaching: The Roles of Fluency and Accuracy. Cambridge: Cambridge University Press.

Bryman, A. \&Cramer, D. (2008). Quantitative data analysis with SPSS 14, 15 and 16: A guide for social scientists. New York: Routledge.

Bulgaru, I. (2015). Cohesion-performance relationship to the educational group level. Procedia - Social and Behavioral Sciences, No. 180, 248-255.

Carron, A.V. \&Brawley, L.R. (2000). Cohesion: Conceptual and measurement issues. Small Group Research, 30(1), pp. 89-106. doi: 10.1177/104649640003100105

Casey-Campbell, M.\&Martens, M.L. (2009). Sticking it all together: a critical assessment of the group cohesionperformance literature. International Journal of Management Reviews, Vol. 11, No. 2, pp. 223-246.

Chelcea, A. (coord.) (1994). Psihoteste (ediţia a doua). Bucureşti: EdituraŞtiinţăşiTehnică SA.

Cohen, L., Manion, L., \&Morrison, K. (2007). Research Methods in Education. Accessed at:http://books.google.com/books?id=iYKKgtngiMC $\& p g=P R 1 \& d q=$ Cohen+Manion, + Morrison $+2007 \& l r=$

Crandall, J. (1999). Cooperative Language Learning and Affective Factors. In J. Arnold (ed.), Affect in Language Learning. Cambridge: Cambridge University Press.

Cristea, D. (2015). Tratat de psihologiesocială. București: Editura TREI.

Dörnyei, Z. \& Murphey, T. (2003). Group Dynamics in the Language Classroom. Cambridge: Cambridge University Press.

Erdley, C.A., Nangle, D.W., \&Gold, J.A. (1998). Operationalizing the Construct of Friendship among Children: A Psychometric Comparison of SociometricBased Definitional Methodologies. Social Development, 7, pp. 62-71.

Fotopoulou, E., Zafeiropoulos, A., \&Alegre, A. (2019). Improving Social Cohesion in Educational Environments Based on A Sociometric-Oriented Emotional Intervention Approach. Education Sciences, 9(24). doi: 10.3390.

George, J.M. (1990). Personality, affect, and behavior in groups. Journal of Applied Psychology, Vol. 75, No. 2, 107-116.

Hackman, J.R. (1990). Groups that work (and those that don't). San Francisco, CA: Jossey-Bass.

Hadfield, J. (1992). Classroom Dynamics. Cambridge: Cambridge University Press.

Hair, J.F., Jr., Black, W.C., Babin, B.J., Andersen, R.E., \&Tatham, R.L. (2006). Multivariate Data Analysis $\left(6^{\text {th }}\right.$ ed.). Upper Saddle River, NJ: Pearson Prentice Hall. 
Hogg, M.A. (1992). The social psychology of group cohesiveness. Toronto: Harvester, Wheatsheaf.

Johnson, D.W. \& Johnson, R.T. (2003). Joining Together: Group Theory and Group Skills ( $8^{\text {th }}$ ed.). Ma: Allyn and Bacon.

Kaplan, D. (1990). Evaluating and modifying covariance models: a review and recommendations. Multivariate Behavioral Research, Vol. 25, No. 2, 137-154.

Karau, S.J. \& Williams, K.D. (1997). The effects of group cohesiveness on social loafing and social compensation. Group Dynamics: Theory, Research, and Practice, 1(2), 156-168.

Kaymak, T. (2011). Group cohesion and performance: A search for antecedents. Ekonomika a Management, No. 4, 78-91.

Klein, K.J., Danserau, F., \&Hall, P.J. (1994). Level issues in theory development, data collection, and analysis. Academy of Management Review, Vol. 19, (2), 195229.

Krâsiko, V.G. (2007). Psihologiasocială. București: Editura EuroPress Group.

Moody, J. \&White, D.R. (2003). Structural Cohesion and Embeddedness: A Hierarchical Concept of Social Groups. American Sociological Review, 68, p. 103-127.

Negovan, V. (2006). Introducere în psihologia educației. București: Editura Universitară.

Sausage, T.V. (1991). Discipline for Self-Control. New Jersey: Prentice Hall.

Senior, R. (2004). A Spirit of Cohesion. English Teaching Professional, 35, 48-50.

\section{Appendix \\ SCALE FOR MEASURING PUPILS CLASS COHESION}

By completing this questionnaire, you will contribute to a research on pupils' opinions on how they feel at school.

Don't worry, all the answers you enter in this material will be treated with the utmost confidentiality. No one but the researchers will have access to your answers.

You need to know that there are no right or wrong answers. Choose the one that suits you best. The important thing is to be honest!
Senior, R.(1997). Transforming Language Classes into Bonded Groups. ELT Journal, 51(1), 3-11.

Sălăvăstru, D. (2004). Psihologiaeducației. Iași: EdituraPolirom.

Senge, P. (2016). Şcoli care învață. A cinceadisciplinăaplicatăîneducație. București: Editura TREI.

Zakriski, A.L., Seifer, R., Sheldrick, R.C, Prinstein, M.J., Dickstein, S, \&Sameroff, A.J. (1999). Child-Focused Versus School-Focused Sociometrics: A Challenge for the Applied Researcher. Journal of Applied Developmental Psychology, 20, 481-499.

Wilt, F., Veen, C., Kruistum, K., \&Oers, B. (2018). Popular, rejected, neglected, controversial, or average: Do young children of different sociometric groups differ in their level of oral communicative competence? Social Development, 27, 793-807.

Woolfolk, A.E. (1993). Educational Psychology ( $5^{\text {th }}$ ed.). US, Ma: Allyn and Bacon.

*** OECD (2010). Educating Teachers for Diversity: Meeting the Challenge. Paris: OECD Publishing. Accessed at:http://dx.doi.org/10.1787/9789264079731-en.

*** OECD (2017). Pupils' sense of belonging at school and their relations with teachers. In PISA 2015 Results (Volume III): Pupils' Well-Being (pp. 117-131). Paris: OECD Publishing. Accessed at: https://doi.org/10.1787/9789264273856-11-en

Please fill in the following data:

\begin{tabular}{|l|l|l|}
\hline \multirow{2}{*}{ Gender } & I am a girl & I am a boy \\
\cline { 2 - 3 } & & \\
\hline Age (in years) & \multicolumn{2}{|c|}{} \\
\hline Grade & \multicolumn{2}{|c|}{} \\
\hline I am living in & urban & Rural area \\
\hline
\end{tabular}

Below you will be presented with a series of 24 sentences about how you feel at school. Please read them carefully and for each of them choose the answer that you think fits you best. The correct answer is marked with an $\mathrm{X}$ in the field of your choice. 


\begin{tabular}{|c|c|c|c|c|c|c|}
\hline \multirow[t]{2}{*}{ No. } & \multirow[t]{2}{*}{ Sentence } & \multicolumn{5}{|l|}{ Your answer } \\
\hline & & $\begin{array}{l}\text { It doesn't fit } \\
\text { me at all }\end{array}$ & $\begin{array}{l}\text { It fits me a } \\
\text { little }\end{array}$ & $\begin{array}{l}\text { It fits me } \\
\text { half }\end{array}$ & $\begin{array}{l}\text { It fits me } \\
\text { a lot }\end{array}$ & $\begin{array}{l}\text { It totally } \\
\text { fits me }\end{array}$ \\
\hline 1 & My classmates involve me in their activities & & & & & \\
\hline 2 & $\begin{array}{l}\text { My classmates exclude me from various } \\
\text { actions }\end{array}$ & & & & & \\
\hline 3 & I feel good at school & & & & & \\
\hline 4 & I have no duties in the children's team & & & & & \\
\hline 5 & I feel attached to my classmates & & & & & \\
\hline 6 & I feel like I don't like my classmates & & & & & \\
\hline 7 & $\begin{array}{l}\text { I rejoice when my class is a winner in a } \\
\text { competition }\end{array}$ & & & & & \\
\hline 8 & $\begin{array}{l}\text { When I have difficulties, I do not turn to my } \\
\text { classmates }\end{array}$ & & & & & \\
\hline 9 & I like the activities carried out with classmates & & & & & \\
\hline $\mathbf{1 0}$ & $\begin{array}{l}\text { When I have a problem, I hide it from my } \\
\text { classmates }\end{array}$ & & & & & \\
\hline 11 & $\begin{array}{l}\text { I communicate easily with the children in the } \\
\text { class }\end{array}$ & & & & & \\
\hline 12 & I don't get help from classmates & & & & & \\
\hline 13 & When I need support, I turn to my classmates & & & & & \\
\hline 14 & I don't feel like I belong to this class & & & & & \\
\hline 15 & I'm proud to be a pupil in this class & & & & & \\
\hline 16 & $\begin{array}{l}\text { I don't like to get involved in activities with my } \\
\text { classmates }\end{array}$ & & & & & \\
\hline 17 & In class I have different tasks & & & & & \\
\hline 18 & $\begin{array}{l}\text { It is difficult for me to participate in group } \\
\text { discussions }\end{array}$ & & & & & \\
\hline 19 & $\begin{array}{l}\text { I have the courage to express my personal } \\
\text { opinion in front of classmates }\end{array}$ & & & & & \\
\hline 20 & $\begin{array}{l}\text { When the class gets a good result, I think it is } \\
\text { not the merit of the whole group }\end{array}$ & & & & & \\
\hline 21 & Classmates help me when I need it & & & & & \\
\hline 22 & My opinion matters little to my classmates & & & & & \\
\hline 23 & When problems arise, I turn to my classmates & & & & & \\
\hline 24 & I'm not proud to be a pupil in this class & & & & & \\
\hline
\end{tabular}

